\title{
THE INFLUENCES OF POPLAR INNER AND OUTER BARK CONTENT ON MECHANICAL PROPERTIES OF WOOD/POLYPROPYLENE COMPOSITES
}

\author{
SEYYED KHALIL HOSSEINIHASHEMI ${ }^{*}$, MOHAMMAD-HADI SHAMSPOUR ${ }^{1}$, VAHIDREZA SAFDARI ${ }^{1}$, \\ SHADEMAN POURMOUSA ${ }^{1}$, NADIR AYRILMIS ${ }^{2}$
}

\author{
${ }^{I}$ Department of Wood Science and Paper Technology, Karaj Branch, Islamic Azad University, Karaj, Iran \\ ${ }^{2}$ Department of Wood Mechanics and Technology, Forestry Faculty, Istanbul University, Bahcekoy, Sariyer, 34473 Istanbul, Turkey
}

\begin{abstract}
This study evaluated the individual and interaction effects of inner bark flour (IBF), outer bark flour (OBF), wood flour (WF), and blending of IBF, OBF, and WF content of poplar tree on the morphology and mechanical properties of wood-plastic composites (WPCs). The IBF, OBF, and WF with 2 wt $\%$ maleic anhydride-grafted polypropylene (MAPP) and polypropylene were compounded into the pellets using a counter-rotating twin-screw extruder. Test specimens were prepared by injection molding machine. The results indicated that the WF alone significantly $(\mathrm{P}<0.05)$ increased the flexural strength, flexural modulus, and tensile strength. The composites made with IBF/WF exhibited higher tensile modulus compared to those made with WF alone and IBF/OBF alone. Moreover, the results showed that the IBF/OBF alone increased the notched impact strength compared to all of reinforced composites. The neat polypropylene had higher notched impact strength than the other reinforced composites $(\mathrm{P}<0.05)$.
\end{abstract}

Keywords: wood-plastic composite, inner and outer bark flour (fiber), wood flour (fiber), mechanical properties, poplar wood.

\section{INTRODUCTION}

Bark is a protective layer on the surface of stems and roots of woody plants. It overlays the wood and consists of inner and outer bark. The inner bark, or the phloem, has xylem and phloem and is a narrow layer of tissue through which the sap moves up and down. The phloem transports sugars produced by photosynthesis throughout the tree. The outer bark (rhytidome) is composed of several layers of tissue collectively known as the periderm and consists of dead wood cells and it is dark-coloured. The outermost layer is made up of dead cork cells which insulates the tree from drying out and protects the inner bark from insect infestation and pathogens that want to gain access to the living tissue [1-3]. The bark is the outer part of the tree stems and branches, and anatomically it is comprised predominantly of parenchyma on the inner side and contains periderm (cork) in its outer side. Bark is not as fibrous as woody parts (xylem) of a tree, and its proportion of fibers is lower than that of woods. Its morphology and chemical composition are different from wood as well [4].

Bark, as a lignocellulosic residue, is mostly used for thermal energy production [5-6] in wood and wood-based panel mills. However, in previous studies it was reported that bark can be used as an alternative raw material in the production of particleboard [6-7], medium fiberboard [8], or WPCs [9-10]. These studies showed that a limited amount of the bark did not significantly affect the mechanical and physical properties of particleboard and fiberboard.

Wood plastic composites (WPC) represent an emerging class of materials that combine the favorable performance and cost attributes of both wood and thermoplastics. Although the technology is not new, there is growing interest in the new design possibilities that this marriage of materials offers. The formulation variations of WPCs that increase wood content offer expansion into other uses, and volume processors must produce faster, better, and cheaper materials. On the other hand, weatherability and life cycle costs are the major factors that restrict the expansion of the field of WPCs [11].

In wood-plastic composites (WPCs) the addition of a natural fiber, such as a reinforcing fiber or filler, results in a new material that performs much better than the individual components and provides a cost reduction of WPCs relative to the plastic alone. Wood-derived fillers or reinforcements are most commonly used in the WPCs industry due to wood fibers' suitable morphological characteristics [12-13], widespread availability, and their ability to be renewed [14].

The effect of different lignocellulosic materials on mechanical characteristics of WPCs has been studied by many researchers, but the use of bark as a thermoplastic filler has not been extensively investigated. Safdari et al. [15] reported that both poplar bark fiber and wood flour significantly increased mechanical properties. Moreover, composites made with bark flour exhibited lower mechanical properties as compared to those made with wood flour and wood flour/bark flour. In other study, Yemele et al. [10] found that most mechanical properties, except for tensile toughness and strain at failure, were lower for spruce bark flour/HPDE composites compared to the control WPC (neat HDPE). Izod impact strength significantly decreased with increase in bark content. The use of MAPP had no significant effect in increasing the mechanical properties and their comparison indicates that in absence of MAPP, bark flour-PP composites exhibited higher mechanical properties than wood flour-PP composite but in presence of MAPP, results were quite inversed [16].

Among the many factors that affect the mechanical and physical properties of composites, the amount and type of lignocellulosics are a salient factor (Bledzki et al. [17]. In wood-plastic composites, increasing the wood fiber loadings initially lead to an increase in some of the mechanical properties $[13,18]$. However, with further increase of the weight percentage of the fillers to WPCs, an optimum threshold is reached, and there is no value in increasing the content of wood fibers [19]. Thus it seems that bark-plastic composites could meet the usual performance requirements if the uses of bark flour have an optimized content in blending with the wood flour. The bark flour can play an important role in the manufacture of thermoplastic composites and may be one of the most efficient uses of the bark.

Based on the extensive literature search, there was no study on the effect of inner and outer bark content the mechanical properties of WPCs. In order to evaluate the effect of the inner and outer bark flour content on the mechanical characteristics of WPCs the bark of poplar wood was selected. The genus Populus is a fast-growing tree that belongs to the Salicaceae family, which comprises of more than 100 species that are distributed in temperate and subtropical regions [20]. In this research the effects of poplar inner and outer bark flour content on the mechanical properties of wood polypropylene (PP) composites were studied.

\section{EXPERIMENTAL}

Materials and methods

Three logs $(1 \mathrm{~m})$ from the poplar tree (Populus alba L.) were cut at breast height and sawn to the boards with $3 \mathrm{~cm}$ thickness and stored at $20^{\circ} \mathrm{C}$ temperature and $65 \%$ relative humidity conditions.

The inner and outer bark, and wood were cut into small pieces and chopped using a laboratory electrical rotary to get inner (IBF) and outer bark (OBF), and wood (WF) flours. The flour size was between 40 and 60 meshes. The IBF, $\mathrm{OBF}$, and WF were dried in an oven at $103 \pm 2{ }^{\circ} \mathrm{C}$ for 24 hours to reach $0 \%$ moisture content and then stored in sealed plastic bags until blending with PP.

Homopolymer PP was obtained from Arak Petrochemical Company (Iran). The melt flow rate of PP (trade name P10800) was 7 to $10 \mathrm{~g}$ per 10 $\mathrm{min}$ at $155-190^{\circ} \mathrm{C}$. Maleic anhydride-grafted polypropylene (MAPP: Alderich 427845) was used as a coupling agent. Polypropylene, MAPP, IBF, OBF, and WF were used according to the different contents listed in Table 1.

Composite preparation

The components of each sample (PP, MAPP, IBF, OBF, and WF) were 
pre-mixed according to Table 1, and homogeneous compounds were prepared and blended in a counter-rotating twin-screw extruder (Dr. Collin system) at a screw speed $70 \mathrm{rpm}$ at $180{ }^{\circ} \mathrm{C}$. The mix was removed from the mixing bowl, cooled in water, and granulated into pellets. The pellets were dried at $85{ }^{\circ} \mathrm{C}$ for $24 \mathrm{~h}$ before injection molding was done. Finally, the pellets were injection molded (Imen Machine Co., Iran) at $160-180{ }^{\circ} \mathrm{C}$ and at a pressure of $10 \mathrm{MPa}$.

Mechanical testing

All of the composites samples were kept at $20 \pm{ }^{\circ} \mathrm{C}$ and $50 \pm 5 \%$ relative humidity before mechanical testing until a constant weight was achieved. The flexural testing including flexural strength (MOR) and flexural modulus (MOE) were performed on an Instron 1186 universal testing machine, according to ASTM test method D-790. The crosshead speed was set at $5 \mathrm{~mm} / \mathrm{min}$. The sample dimensions for flexural tests were $105 \mathrm{~mm} \times 10 \mathrm{~mm} \times 10 \mathrm{~mm}$.

The tensile properties of each specimen were tested with an INSTRON 1186 universal testing machine, according to ASTM test method D-638. The Sample dimensions for tensile property testing were $145 \mathrm{~mm} \times 10 \mathrm{~mm} \times 4 \mathrm{~mm}$.
The notched Izod impact strength test was conducted with SANATAM machine, according to ASTM test method D-256. The Sample dimensions for notched Izod impact test were $60 \mathrm{~mm} \times 12 \mathrm{~mm} \times 6 \mathrm{~mm}$.

Statistical analysis

Statistical analysis was performed using ANOVA (SPSS). The 10 formulation designs, which are shown in Table 1, were all analyzed for variance using a complete randomized block design. Testing of mechanical properties was performed using 4 replicates of each formulation. Property means were compared using Duncan's new multiple range test at a 95\% confidence level, as shown in Figures 1-6.

Morphological analysis of fracture surface of composites

Scanning electron microscopy (SEM) was used to monitor the fracture surface of the composites. SEM analysis was performed using a Philips XL30 (Holland) instrument. The samples were sputtered with a layer of gold/ palladium before imaging.

Table 1: Experimental design for inner and outer bark and wood-plastic composites formulations.

\begin{tabular}{|c|c|c|c|c|c|}
\hline Composite type & \multicolumn{5}{|c|}{ Component } \\
\hline & $\begin{array}{c}\text { IBF } \\
(\mathrm{wt} \%)\end{array}$ & $\begin{array}{c}\text { OBF } \\
(\mathrm{wt} \%)\end{array}$ & $\begin{array}{c}\text { WF } \\
(\mathrm{wt} \%)\end{array}$ & $\begin{array}{c}\text { PP } \\
(\mathrm{wt} \%)\end{array}$ & $\begin{array}{c}\text { MAPP } \\
(\mathrm{wt} \%)\end{array}$ \\
\hline A & 14 & 14 & 0 & 70 & 2 \\
\hline B & 0 & 14 & 14 & 70 & 2 \\
\hline C & 14 & 0 & 14 & 70 & 2 \\
\hline D & 0 & 38 & 0 & 60 & 2 \\
\hline E & 38 & 0 & 0 & 60 & 2 \\
\hline F & 0 & 0 & 38 & 60 & 2 \\
\hline G & 0 & 21.5 & 21.5 & 55 & 2 \\
\hline H & 21.5 & 0 & 21.5 & 55 & 2 \\
\hline I & 21.5 & 21.5 & 0 & 65 & 0 \\
\hline J & 11 & 11 & 11 & 100 & 2 \\
\hline K & 0 & 0 & 0 & & 2 \\
\hline
\end{tabular}

$\mathrm{IBF}=$ Inner bark flour; $\mathrm{OBF}=$ Outer bark flour; $\mathrm{WF}=$ Wood flour; $\mathrm{PP}=$ polypropylene; $\mathrm{MAPP}=$ Polypropylene maleic anhydride.

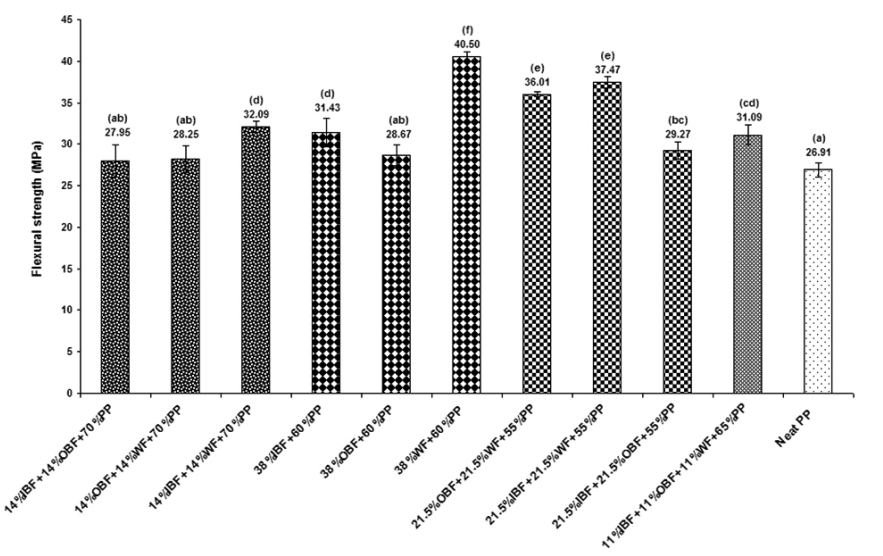

Figure 1. Mean values of the IBF/PP, OBF/PP, WF/PP, IBF/OBF/PP, IBF/ WF/PP, OBF/WF/PP, IBF/OBF/WF/PP, and neat PP composites. Duncan's multiple range tests are given in parentheses. The different alphabetical designations indicate that there is a significant difference between different treatments (composites).

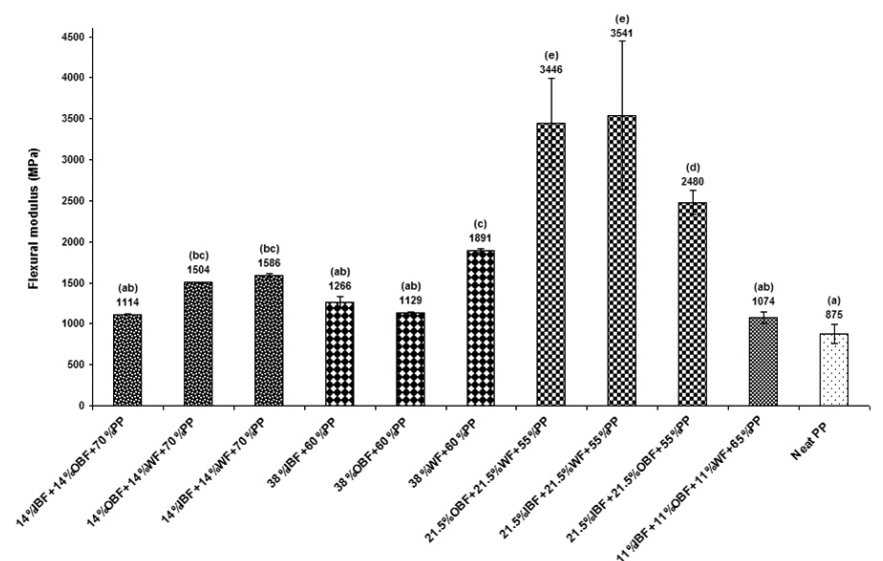

Figure 2. Mean values of the IBF/PP, OBF/PP, WF/PP, IBF/OBF/PP, IBF/ WF/PP, OBF/WF/PP, IBF/OBF/WF/PP, and neat PP composites. Duncan's multiple range tests are given in parentheses. The different alphabetical designations indicate that there is a significant difference between different treatments (composites). 


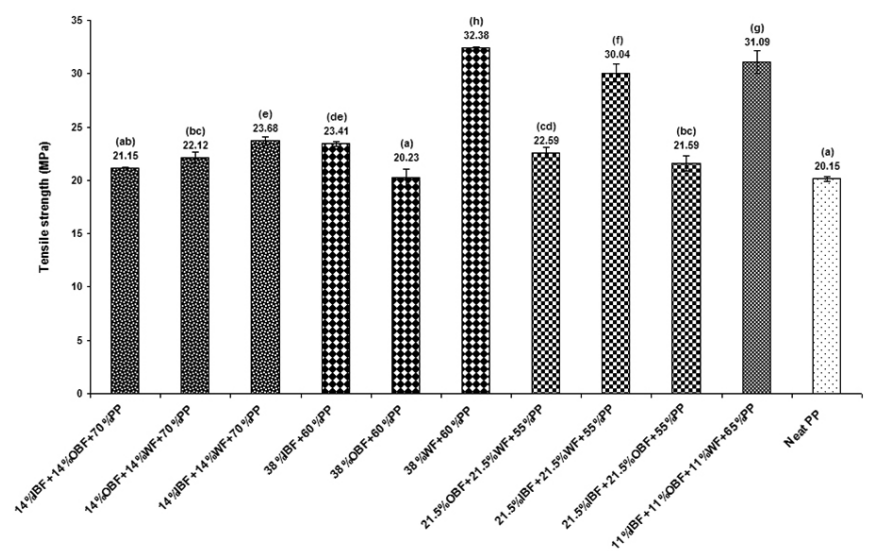

Figure 3. Mean values of the IBF/PP, OBF/PP, WF/PP, IBF/OBF/PP, IBF/ WF/PP, OBF/WF/PP, IBF/OBF/WF/PP, and neat PP composites. Duncan's multiple range tests are given in parentheses. The different alphabetical designations indicate that there is a significant difference between different treatments (composites).

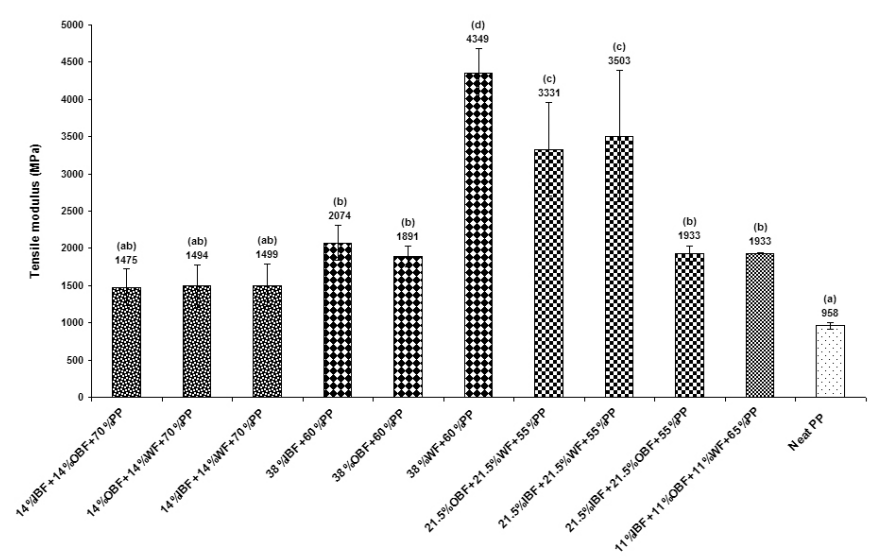

Figure 4. Mean values of the IBF/PP, OBF/PP, WF/PP, IBF/OBF/PP, IBF/ $\mathrm{WF} / \mathrm{PP}, \mathrm{OBF} / \mathrm{WF} / \mathrm{PP}, \mathrm{IBF} / \mathrm{OBF} / \mathrm{WF} / \mathrm{PP}$, and neat PP composites. Duncan's multiple range tests are given in parentheses. The different alphabetical designations indicate that there is a significant difference between different treatments (composites).

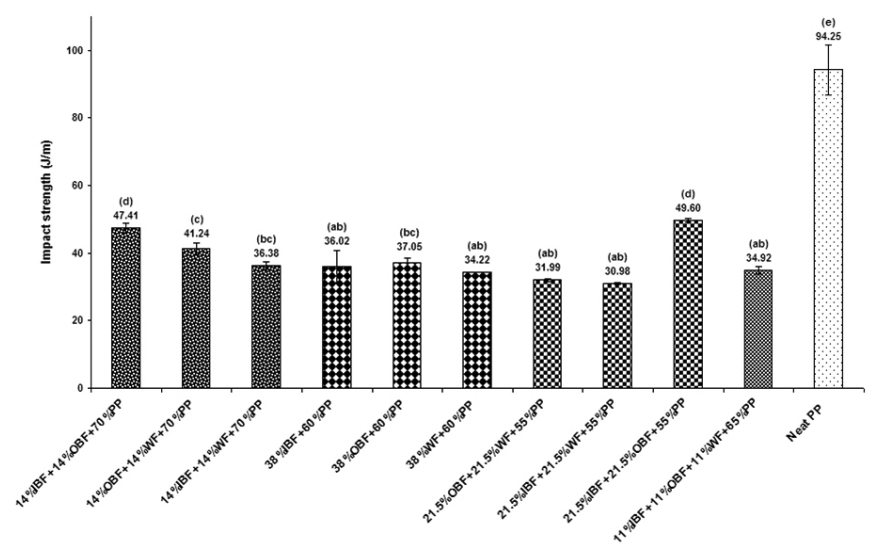

Figure 5. Mean values of the IBF/PP, OBF/PP, WF/PP, IBF/OBF/PP, IBF/ $\mathrm{WF} / \mathrm{PP}, \mathrm{OBF} / \mathrm{WF} / \mathrm{PP}, \mathrm{IBF} / \mathrm{OBF} / \mathrm{WF} / \mathrm{PP}$, and neat PP composites. Duncan's multiple range tests are given in parentheses. The different alphabetical designations indicate that there is a significant difference between different treatments (composites).
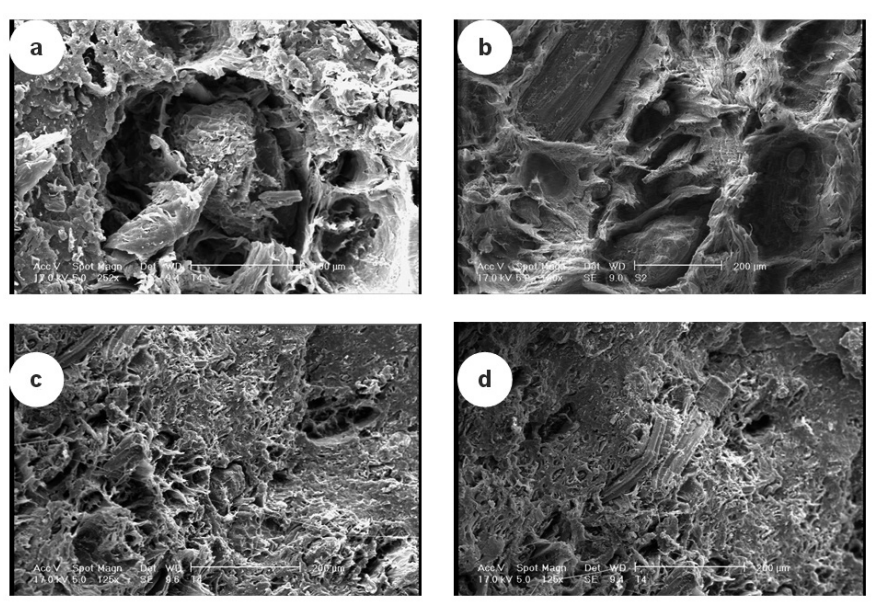

Figure 6. Fracture surface of flexural samples of some compositions: (a) $14 \% \mathrm{IBF}+14 \% \mathrm{OBF}+70 \% \mathrm{PP}$; (b) $38 \% \mathrm{OBF}+60 \% \mathrm{PP}$; (c) $38 \% \mathrm{WF}+$ $60 \% \mathrm{PP}$, and (d) $21.5 \% \mathrm{IBF}+21.5 \% \mathrm{WF}+55 \% \mathrm{PP}$. By increasing the WF content the proportion of fines is reduced, the dispersion of flour gets better ( $\mathrm{C}$ $\&$ d), the presence of outer bark causes voids, and delamination in composites and strength are reduced ( $\&$ b). By increasing IBF and WF contents, the dispersion of fillers gets better, voids decrease, and strength increases in composites (c \& d).

\section{RESULTS AND DISCUSSION}

Flexural properties

The flexural properties of the composites are presented in Figures1 and 2, As shown in the Figures, the MOR and MOE values ranged from $27.95 \mathrm{MPa}$ to $40.50 \mathrm{MPa}$ and $1074 \mathrm{MPa}$ to $3541.33 \mathrm{MPa}$, in the reinforced composites, respectively. The composites $\mathrm{IBF} / \mathrm{OBF} / \mathrm{PP}$ and $\mathrm{IBF} / \mathrm{OBF} / \mathrm{WF} / \mathrm{PP}$ exhibited the lowest MOR and MOE, respectively. Among the BF/PP conditions, the $14 \%$ the IBF/OBF content showed the lowest MOR and it was significantly different from the treatments having less OBF content. By increasing the WF content from 11 to $38 \%$, the MOR increased significantly. Among the IBF/WF/ PP composites, the optimum content for improving the flexural and modulus strength was found to be $21.5 \%$.

By adding WF and IBF into the composites and by increasing the flour content the MOR increases, but by adding OBF into the composites and by increasing the flour content the MOR decreased. By adding IBF and OBF into the $\mathrm{WF} / 55 \% \mathrm{PP}$ composites and by increasing the bark flour content to $21.5 \%$ the MOE increased, but in other composites including 70,65 , and $60 \%$ PP by increasing and decreasing the each type of flour the MOE decreased. The results showed that the IBF flour more increased the MOR and MOE of the composites than the OBF flour. The MOR and MOE of the wood flour filled HDPE composites were better than that of the bark flour filled HDPE composites. Similar results were found in previous studies [10,15,21]. This was mainly due to higher cellulose content of the wood flour. Cellulose is mainly responsible for the strength in lignocellulosics.

The low effect of the OBF on the MOR can be attributed to the fines and low aspect ratio (length/width) of OBF in PP matrix [22], the lower intrinsic fiber strength of outer bark fibers compared to inner bark and wood fibers [10], lower cellulose (polysaccharide) content of the outer bark fillers than inner bark wood [9], and delaminating between fines and PP (Figure 6). A higher amount of extractives in outer bark can cause a weak surface layer and make the coupling agent less effective in forming a cross-linking network with the cellulose [23].

When the IBF and OBF were blended with WF, the MOR and MOE increased compared to the composites containing only the IBF and OBF. In all the treatments by increasing the flour content, the MOR and MOE improved. For example, despite the fact that some compositions used were blended with $\mathrm{IBF} / \mathrm{WF} / \mathrm{PP}$ and $\mathrm{OBF} / \mathrm{WF} / \mathrm{PP}$ such as $70 \% \mathrm{PP}+14 \% \mathrm{OBF}+14 \% \mathrm{WF}$, the MOR and modulus didn't show a significant difference with some compositions that used IBF/WF/PP (70\% PP + 14\% IBF + 14\% WF). This can be attributed to the fiber content. The content of fiber in later composition was lower than the former composition. However, as there was a better quality of WF compared to $\mathrm{OBF}$, the lower fiber content was compensated. This results in there being no significant differences between the two composites. 
Among the compositions having the mixtures of IBF/WF/PP and OBF/ $\mathrm{WF} / \mathrm{PP}$ together, the composite of $55 \% \mathrm{PP}+21.5 \% \mathrm{IBF}+21.5 \% \mathrm{WF}$ and $55 \%$ $\mathrm{PP}+21.5 \% \mathrm{OBF}+21.5 \% \mathrm{WF}$ that had the highest lignocellulosic flour content also had greater MOR and MOE. The composites of WF/PP showed the highest MOE, and it comprised $60 \% \mathrm{PP}+38 \% \mathrm{WF}$. These results showed significant differences with all the other treatments. In the composites of $60 \% \mathrm{PP}+38 \%$ $\mathrm{OBF}$, despite their having a higher content of the OBF, their MOR and MOE were lower than those of other treatments with lower content of WF or OBF/ WF. This revealed that the fiber content cannot be the sole important factor in increasing the MOR, and other factors, i.e., morphological and chemical characteristics of fibers and intrinsic fiber strength should be considered [15].

Tensile properties

Tensile properties of the composites are presented in Figures 3 and 4. The tensile strength and tensile modulus ranged from 20.23 to $32.38 \mathrm{MPa}$ and 1475 to 4349 in the composites, respectively. The tensile strength of the composites prepared with the $\mathrm{OBF} / \mathrm{PP}$ and $\mathrm{IBF} / \mathrm{OBF} / \mathrm{PP}$ was lower than other composites. The composites comprising WF/PP showed the best tensile strength and tensile modulus among all other compositions. The composites having more than $11 \%$ OBF (i.e. $14 \%, 21.5 \%$, and $38 \%$ OBF) and lower than $38 \%$ IBF (i.e. $14 \%$ IBF) were not significantly different from each other with respect to tensile strength. Among the $\mathrm{BF} / \mathrm{PP}$ composites, the optimum content for improving the tensile strength and tensile modulus was $21.5 \% \mathrm{IBF}$.

By adding the IBF and OBF to the WF $/ 55 \%$ PP composites and by increasing the flour content to $21.5 \%$ the tensile strength and modulus increased. However, in other composites including $70 \%, 65 \%$, and $60 \% \mathrm{PP}$ by increasing and decreasing the each type of flour, the tensile strength and modulus decreases with except of $38 \% \mathrm{WF} / 60 \% \mathrm{PP}$.

The weak effectiveness of OBF in comparison to the IBF and WF with respect to the tensile strength could be due to the low slenderness ratio of outer bark fibers [12], poor fine fiber dispersion in the plastic matrix, resulting in stress concentration [24], and lower intrinsic fiber strength of outer bark fibers compared to inner bark and wood fibers. Poor bark-plastic adhesion between outer bark fiber and the coupling agent was reported by previous some researchers and can be one of the reasons that may account for lower tensile strength $[18,25]$.

The tensile strength and modulus of the composites improved with increasing the WF content. The composition $60 \% \mathrm{PP}+38 \% \mathrm{OBF}$, had higher bark flour content than $60 \% \mathrm{PP}+38 \% \mathrm{WF}$, however due to the presence of WF in the former composition, the tensile strength and modulus were significantly higher. This proved that the effect of fiber content on mechanical properties was dependent on the intrinsic fiber strength and fiber size. These results are in good agreement with results from other researchers that reported by increasing the particle size [26] or, slenderness ratio, flexural and tensile modulus and strength tend to increase [12]

Impact strength

The impact strength of the composites ranged from $30.98 \mathrm{~J}^{-1} \mathrm{~m}^{-1}$ to 49.60 $\mathrm{J} . \mathrm{m}^{-1}$ (Figure 5). The compositions containing medium flour $(21.5 \% \mathrm{IBF}+$ $21.5 \% \mathrm{OBF})$ and less polypropylene (55\% PP) had higher impact strength. This was mainly attributed to the lack of compatibility between the phases and also the addition of bio-resource fiber content creates regions of stress concentration that require less energy to initiate a crack in samples [14]. Thus, the composites reinforced with lignocellulosic material were more brittle and exhibited lower notched impact strength.

Morphological analysis

The SEM images of the fractured composite specimens produced with the IBF, OBF, WF, and a mixture of these components are presented in Figure 6. In contrast to the outer bark, most cells in inner bark and wood tissue are fibrous. However, the outer bark is made up of paranchymatous ground tissue; the cells are short and thin. It is due to this characteristic that the OBF was much finer than IBF and WF. The outer bark fibers are not as abundant as the inner bark and woody parts. The outer bark is much shorter and thicker than inner bark and wood fibers and their aspect ratios (fiber length/fiber width) are not as high as inner bark and wood fibers. These differences are apparent in the mechanical properties and the SEM images in Figure 6.

It seems that the differences in the chemical composition among the outer bark, inner bark, and wood, fines, low aspect ratio (length/width) of bark flour, delamination between fines and matrix, and the lower intrinsic fiber strength of outer bark fibers compared to inner bark and wood fibers are good explanations for this demarcation.

\section{CONCLUSION}

The IBF, OBF and WF composites exhibited significantly increased mechanical properties in comparison to neat polypropylene. However the notched impact strength reduced with increasing bark flour content. Despite the increase in mechanical properties, the effect of IBF and OBF on the mechanical properties was significant in comparison to the neat PP, but its effectiveness was minor. However by adding the WF to the composites, the mechanical characteristics recovered significantly but never approached those of the composite made with the WF/PP. The composites made with the OBF exhibited lower mechanical properties compared to those made with the IBF and WF. The differences was mainly attributed to the factors which were different chemical composition between inner bark, outer bark, and wood, fines and low slenderness ratio of the $\mathrm{OBF}$, the poor dispersion of the $\mathrm{OBF}$, and also the lower intrinsic fiber strength of outer bark fibers compared to the inner bark, wood fibers. The effect of fiber content on the mechanical properties was positive for the composites made with the IBF/WF/PP and WF/PP and negative for those composite made with the OBF/PP. Thus, the effect of fiber content on the mechanical properties was dependent on the intrinsic fiber characteristics. The OBF alone cannot reinforce the polypropylene composite suitably and it is better to be blended with the IBF and WF.

\section{ACKNOWLEDGMENTS}

The authors are grateful for the financial support of the Department of Wood Science and Technology, Karaj Branch, Islamic Azad University.

\section{REFERENCES}

1. P. Hakkila, Structure and properties of wood and woody biomass, Kellomaki, S. (Ed.), Fapet Oy, Jyvaskyla, Finland (1998).

2. G. A. Smook, Handbook for Pulp and Paper Technologists, 2nd edition, Angus Wilde Publications Inc., Vancouver, Canada (1992).

3. K. Wolfe, A. Hitchcock, Tree Bark, http://ext100.wsu.edu/skagit/wpcontent/uploads/sites/5/2014/03/Learn-to-Identify-Trees-by-Their-Bark. pdf (2015).

4. J. M. Harkin, J. M. Rowe, Bark and its possible uses, USDA For. Serv. For. Prod. Lab. Res. Note FPl-091 (1971).

5. B. Klasnja, S. Kopitovic, S. Orlovic, J. Biomass and Bioenergy, 23, 427432 (2002).

6. M. C. N. Yemele, A. Koubaa, P. Blanchet, A. Cloutier, M. Wolcott, J. Forest Prod, 58, 48-56 (2008).

7. P. Blanchet, A. Cloutier, B. Riedl, Wood Sci. and Technol, 34, 11-9 (2000).

8. C. Xing, J. Deng, S. Y. Zhang, B. Riedl, A. Cloutier, J. Forest Prod, 56, 64-69 (2006).

9. D. P. Harper, T. L. Eberhardt, 10th International Conference on Wood \& Biofiber Plastic Composites. Madison, WI: Forest Prod. Soc, 248-252 (2010).

10. M. C. N. Yemele, A. Koubaa, A. Cloutier, P. Soulounganga, A. Koubaa, Composites Part A: J. Appl. Sci. and Manufact, 41, 131-137 (2010).

11. O. Faruk, A. K. Bledzki, Wood Plastic Composite: Present and Future, John Wiley \& Sons, Inc. University of Toronto, Toronto,. ON, Canada. (2012).

12. N. M. Stark, R. E. Rowlands, J. Wood Fiber Sci, 35, 167-74 (2003).

13. F. Basiji, V. Safdari, A. Nourbakhsh, S. Pilla, J. Turk. Agric. For, 34, 191196 (2010).

14. R. M. Rowell, A. R. Sanadi, D. F. Caulfield, E. Jacobson, In: Lignocellulosic-Plastic Composites, A. L. Leão, F. X. Carvalho, E. Frollini, (Eds.), São Paulo, USP \& UNESP, $23-51$ (1997).

15. V. Safdari, H. Khodadadi, S. K. Hosseinihashemi, E. Ganjian, BioRes, 6, 5180-5192 (2011)

16. S. Kazemi Najafi, A. Azimi Delarestaghi, Iranian J. Wood and Paper Sci. Res, 26, 811-823 (2012).

17. A. K. Bledzki, J. Gassan, S. Theis, J. Mech. Compos. Mat, 34, 563-568 (1998).

18. H. Bouafif, A. Koubaa, P. Perre, A. Cloutier, Composites Part A: J. Appl. Sci. Manufact, 40, 1975-1981 (2009).

19. J. Z. Lu, Q. Wu, I. I. Negulescu, J. Appl. Polym. Sci, 96, 93-102 (2005).

20. X. Wang, Q. Wang, G. J. Xu, L. S. Xu, Wood Sci. and Technol, 45, 5-13 (1999).

21. N. S. Cetin, N. Özmen, N. Narlıoğlu, V. Cavus, Usak Univ., J. Mat. Sci, 1, 23-32 (2014).

22. S. Migneault, A. Koubaa, F. Erchiqui, A. Chaala, K. Englund, M. P. 
Wolcott, Composites Part A: J. Appl. Sci. Manufact, 40, 80-85 (2009).

23. H. Saputra, J. Simonsen, K. Li, Compos. Inter, 11, 515-524 (2004).

24. K. E. Gamstedt, P. Nygard, M. Lindström, In: Proc. 3e symposium international sur les composites bois polymères, Bordeaux, France, 26-27 (2007).
25. H. Bouafif, A. Koubaa, P. Perre, A. Cloutier, B. Riedl, J. Wood Chem. and Technol, 28, 296-315 (2008)

26. N. M. Stark, M. J. Berger, 4th Intl. Conf. Wood Fiber-plastic Compos., Madison, (1997). 